\title{
Relation of birth weight and childhood respiratory infection to adult lung function and death from chronic obstructive airways disease
}

\author{
D J P Barker, K M Godfrey, C Fall, C Osmond, P D Winter, S O Shaheen
}

\begin{abstract}
Objective-To examine whether birth weight, infant weight, and childhood respiratory infection are associated with adult lung function and death from chronic obstructive airways disease.

Design-Follow up study of men born during 1911-30 whose birth weights, weights at 1 year, and childhood illnesses were recorded at the time by health visitors.
\end{abstract}

Setting-Hertfordshire, England.

Subjects -5718 men born in the county during 1911-30 and a subgroup of 825 men born in the county during 1920-30 and still living there.

Main outcome measures-Death from chronic obstructive airways disease, mean forced expiratory volume in one second $\left(\mathrm{FEV}_{1}\right)$ and forced vital capacity (FVC), and respiratory symptoms.

Results - 55 men died of chronic obstructive airways disease. Death rates fell with increasing birth weight and weight at 1 year. Mean FEV $_{1}$ at age 59 to 70 years, adjusted for height and age, rose by 0.06 litre $(95 \%$ confidence interval 0.02 to 0.09$)$ with each pound $(450 \mathrm{~g})$ increase in birth weight, independently of smoking habit and social class. Bronchitis or pneumonia in infancy was associated with a 0.17 litre $(0.02$ to 0.32$)$ reduction in adult $\mathrm{FEV}_{1}$ and with an increased odds ratio of wheezing and persistent sputum production in adult life independently of birth weight, smoking habit, and social class. Whooping cough in infancy was associated with a 0.22 litre $(0.02$ to 0.42$)$ reduction in adult $\mathrm{FEV}_{1}$.

Conclusions-Lower birth weight was associated with worse adult lung function. Intrauterine influences which retard fetal weight gain may irrecoverably constrain the growth of the airways. Bronchitis, pneumonia, or whooping cough in infancy further reduced adult lung function. They also retarded infant weight gain. Consistent with this, death from chronic obstructive airways disease in adult life was associated with lower birth weight and weight at 1 year. Promoting lung growth in fetuses and infants and reducing the incidence of lower respiratory tract infection in infancy may reduce the incidence of chronic obstructive airways disease in the next generation.

\section{Introduction}

Evidence from several sources suggests that infection of the lower respiratory tract in early childhood may impair lung function in adult life and lead to respiratory symptoms. Follow up studies of infants and young children who have had bronchitis, bronchiolitis, or pneumonia show that there are persisting abnormalities of lung function up to the age of 10 years..$^{1-3}$ In a sample of British children born in 1946 and followed up to age 36 years those reported as having had one or more lower respiratory infections before 2 years of age had a higher prevalence of cough during the day or night in winter and a lower peak expiratory flow rate.

Though there is no direct evidence that childhood respiratory infection is linked with clinically significant obstructive lung disease, the findings of geographical studies point to such a link. Differences in death rates from chronic bronchitis and emphysema in the 212 local authority areas in England and Wales are strongly related to differences in infant mortality from bronchitis and pneumonia 70 years ago and before. ${ }^{5}$ The distributions of respiratory disease in childhood and late adult life internationally are also similar. ${ }^{6}$ Studies of British born men who migrated to other parts of the country or to the United States show that the prevalence of obstructive lung disease is associated with the place of birth independently of the place of current residence. $^{78}$

Lower respiratory tract infections are more common among infants with low birth weight. ${ }^{9}$ In later childhood these infants have a higher prevalence of cough and worse lung function than infants with normal birth weight. ${ }^{10}$ We do not yet know whether birth weight relates to adult lung function or obstructive lung disease. Such a relation could result either from the association between lower birth weight and infant respiratory infection or an association between birth weight and lung size, as growth of the airways is largely completed in utero."

In Hertfordshire, England, the birth weights of all babies born in the county have been recorded since 1911. From 1923 onwards information on illnesses up to the age of 5 years has also been recorded. These data allow birth weight and childhood respiratory infection to be related to adult lung function and death from chronic obstructive airways disease.

\section{Subjects and methods}

In Hertfordshire from 1911 onwards all births were notified by the attending midwife. Health visitors saw the children at home periodically throughout infancy (the first year of life). From 1923 onwards the health visitors continued to see the child up to the age of 5 years. They recorded birth weight, infant weight, and whether the infant was breast fed from birth or bottle fed. They followed the child's development and noted the occurrence of illnesses. Illnesses occurring up to the age of 1 year and between the ages of 1 and 5 years were recorded in separate sections of each child's record, but the precise age at which each illness occurred was not generally recorded. Weights were measured in pounds $(2 \cdot 2 \mathrm{lb}=1 \mathrm{~kg})$ and were often rounded to the nearest pound or half pound. We therefore used the original units.

The health visitors' records have been preserved. We are tracing all singleton babies born in the county

Professor Barket.

$B M F 1991 ; 303: 671-5$ 
TABLE I-Standardised mortality ratios (numbers of deaths) for chronic obstructive airways disease and lung cancer in 5718 men according to birth weight and weight at 1 year

\begin{tabular}{|c|c|c|}
\hline & $\begin{array}{c}\text { Chronic } \\
\text { obstructive } \\
\text { airways disease }\end{array}$ & $\begin{array}{c}\text { Lung } \\
\text { cancer }\end{array}$ \\
\hline \multicolumn{3}{|c|}{$\begin{array}{l}\text { Weight }(\mathrm{lb}) \text { : } \\
\text { At } 1 \text { year }\end{array}$} \\
\hline$\leqslant 18 \cdot 0$ & $111(6)$ & $87(11)$ \\
\hline$-20 \cdot 0$ & $87(13)$ & $99(35)$ \\
\hline$-22 \cdot 0$ & $65(17)$ & $91(58)$ \\
\hline$-24 \cdot 0$ & $60(13)$ & $59(31)$ \\
\hline$-26 \cdot 0$ & $44(5)$ & $96(26)$ \\
\hline$\geqslant 27 \cdot 0$ & $25(1)$ & $61(6)$ \\
\hline \multicolumn{3}{|l|}{ At birth } \\
\hline$\leqslant 5 \cdot 5$ & $131(5)$ & $110(10)$ \\
\hline$-6 \cdot 5$ & $69(7)$ & $96(24)$ \\
\hline$-7 \cdot 5$ & $80(18)$ & $73(40)$ \\
\hline$-8 \cdot 5$ & $46(12)$ & $86(54)$ \\
\hline$-9 \cdot 5$ & $79(11)$ & $67(22)$ \\
\hline$>9.5$ & $28(2)$ & $103(17)$ \\
\hline All & $66(55)$ & $83(167)$ \\
\hline
\end{tabular}

TABLE II-Mean forced expiratory volume in one second adjusted for height and age among men aged 59-70, according to birth weight

\begin{tabular}{ccc}
\hline $\begin{array}{c}\text { Birth } \\
\text { weight } \\
\text { (lb) }\end{array}$ & No of men & $\begin{array}{c}\text { Forced } \\
\text { expiratory } \\
\text { volume }(1)\end{array}$ \\
\hline$\leqslant 5 \cdot 5$ & 33 & $2 \cdot 28$ \\
-6.5 & 103 & 2.41 \\
$-7 \cdot 5$ & 258 & 2.44 \\
-8.5 & 242 & $2 \cdot 52$ \\
$-9 \cdot 5$ & 132 & 2.55 \\
$>9 \cdot 5$ & 57 & $2 \cdot 57$ \\
\hline All & 825 & $2.48^{\star}$
\end{tabular}

*Standard deviation $=0 \cdot 59$. during 1911-30 who had birth weight and weight at 1 year recorded. Because tracing of women is complicated by change of name at marriage the present study is limited to men. In six registration districts of east Hertfordshire tracing has been completed and the whereabouts of 5718 men $(74 \%)$ is known. We analysed deaths from chronic obstructive airways disease (ICD (ninth revision) codes 491-493 and 496) and lung cancer (ICD codes 162-164) in relation to birth weight and weight at 1 year. Most of the deaths had occurred in men born before 1923, for whom childhood illnesses were not recorded. The numbers of deaths were compared with those expected from national rates for men of corresponding age and year of birth. Death rates were expressed as standardised mortality ratios, with the national average being taken as 100 .

Of the men born in the six districts during 1920-30, 1157 still live there. They are an accessible and not too elderly sample; $845(73 \%)$ of them agreed to be visited at home. They were interviewed by one of four fieldworkers, who had not seen the health visitors' records. Each man was asked about his medical and social history, including standard questions approved by the Medical Research Council on respiratory symptoms. ${ }^{12}$ Father's occupation was used to define social class at birth, and current social class was derived from the man's occupation. Before starting the study the procedures for the measurements were standardised and the fieldworkers trained. Lung function was measured with a handheld turbine microspirometer (Micro Medical). After practice blows, and once reproducibility in an individual subject had been obtained, forced expiratory volume in one second $\left(\mathrm{FEV}_{1}\right)$ and forced vital capacity (FVC) were measured three times. The highest of the three values was analysed. ${ }^{1314}$ Height was measured with a portable stadiometer. Statistical analysis was carried out using multiple regression; odds ratios were calculated by logistic regression. ${ }^{15}$

\section{Results}

Of the 5718 men, 55 had died from chronic obstructive lung disease. The death rate was below the national average, the standardised mortality ratio being 66 . Table I shows that standardised mortality ratios fell

TABLE III-Mean forced expiratory volume in one second (litres) adjusted for height and age among men aged 59-67, according to birth weight and bronchitis or pneumonia and whooping cough in infancy. Numbers of men in parentheses

\begin{tabular}{llllll}
\hline & \multicolumn{2}{c}{$\begin{array}{c}\text { Bronchitis or pneumonia } \\
\text { in infancy }\end{array}$} & & \multicolumn{2}{c}{$\begin{array}{c}\text { Whooping cough } \\
\text { in infancy }\end{array}$} \\
\cline { 2 - 3 } \cline { 6 - 6 } $\begin{array}{l}\text { Birth } \\
\text { weight (lb) }\end{array}$ & Absent & Present & & Absent & Present \\
\hline 55.5 & $2.39(22)$ & $1.81(4)$ & & $2.30(26)$ & \\
-6.5 & $2.40(70)$ & $2.23(10)$ & & $2.38(78)$ & $2.39(2)$ \\
-7.5 & $2.47(163)$ & $2.38(25)$ & & $2.47(175)$ & $2.29(13)$ \\
-8.5 & $2.53(179)$ & $2.33(12)$ & & $2.53(183)$ & $2.40(8)$ \\
-9.5 & $2.54(103)$ & $2.36(5)$ & & $2.56(103)$ & $2.00(5)$ \\
$>9.5$ & $2.57(43)$ & $2.36(3)$ & & $2.57(43)$ & $2.30(3)$ \\
\hline All & $2.50(580)$ & $2.30(59)$ & $2.49(608)$ & $2.28(31)$
\end{tabular}

TABLE IV - Difference in lung volumes adjusted for height, age, and birth weight between men who had had recorded childhood illnesses and other men

Differences (1) ( $95 \%$ confidence interval)

\begin{tabular}{|c|c|c|c|c|}
\hline Childhood illness & $\begin{array}{c}\text { Age } \\
\text { (years) }\end{array}$ & $\begin{array}{l}\text { No of } \\
\text { men }\end{array}$ & $\begin{array}{c}\text { Mean forced } \\
\text { expiratory volume }\end{array}$ & Mean forced vital capacity \\
\hline \multirow[t]{2}{*}{ Bronchitis or pneumonia } & $<1$ & 59 & $-0.17(-0.32$ to -0.02$)$ & $-0.24(-0.40$ to -0.07$)$ \\
\hline & $1-4$ & 63 & $-0.04(-0.19$ to 0.11$)$ & $-0.06(-0.22$ to 0.11$)$ \\
\hline \multirow[t]{2}{*}{ Whooping cough } & $<1$ & 31 & $-0.22(-0.42$ to -0.02$)$ & $-0.31(-0.54$ to -0.09$)$ \\
\hline & $1-4$ & 124 & $-0.11(-0.22$ to 0.00$)$ & $-0.09(-0.22$ to 0.03$)$ \\
\hline \multirow[t]{2}{*}{ Measles } & $<1$ & 20 & $0.17(-0.09$ to 0.42$)$ & $0 \cdot 10(-0.18$ to 0.38$)$ \\
\hline & $1-4$ & 134 & $-0.06(-0.17$ to 0.05$)$ & $-0.04(-0.16$ to 0.08$)$ \\
\hline
\end{tabular}

progressively from 111 in men who had weighed $\leqslant 18 \mathrm{lb}$ at 1 year to 25 in men who weighed $\geqslant 27 \mathrm{lb}\left(\chi^{2}\right.$ for trend $=4 \cdot 5, p=0 \cdot 03)$. There was a weak trend of falling standardised mortality ratios with increasing birth weight $\left(\chi^{2}\right.$ for trend $\left.=2 \cdot 6, \mathrm{p}=0 \cdot 11\right)$. There were no similar trends for lung cancer.

Complete data were obtained from 825 of the 845 men visited at home; their ages ranged from 59 to 70

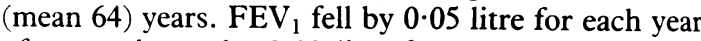
of age and rose by 0.03 litre for each centimetre of height. We therefore standardised all volumes for age and height with regression. The mean adjusted FEV was 2.48 (SD 0.59) litres. Mean $\mathrm{FEV}_{1}$ rose progressively with increasing birth weight, rising by 0.06 litre $(95 \%$ confidence interval 0.02 to $0.09, \mathrm{p}=0.0007)$ with each pound increase in birth weight (table II). One standard deviation increase in birth weight was associated with a 0.07 litre increase in $\mathrm{FEV}_{1}$. The corresponding increase for current height was $0 \cdot 17$ litre.

Table III shows the mean $\mathrm{FEV}_{1}$ values of the 639 men born from 1923 onwards, when childhood illnesses were recorded. Fifty nine men were recorded as having had an attack of bronchitis or pneumonia during infancy. Their mean birth weight was $7.5 \mathrm{lb}$ compared with $7.9 \mathrm{lb}$ in all other men (difference $0.4 \mathrm{lb}$ $(0 \cdot 1$ to $0 \cdot 8))$. At each birth weight their mean $\mathrm{FEV}_{1}$ was lower than that of men not recorded as having had bronchitis or pneumonia. After allowing for the birth weight distribution their mean $\mathrm{FEV}_{1}$ was 0.17 litre lower (table IV). Sixty three men were recorded as having had an attack of bronchitis or pneumonia between 1 and 5 years of age. Their mean $\mathrm{FEV}_{1}$ after adjustment for birth weight was similar to that of all other men (table IV).

Thirty one men were recorded as having had whooping cough during infancy, only four of whom had also had bronchitis or pneumonia. Table III shows that the mean $\mathrm{FEV}_{1}$ of those who had had whooping cough in infancy tended to be lower than that of other men who had the same birth weight. After allowing for the distribution of birth weight their mean $\mathrm{FEV}_{1}$ was 0.22 litre lower (table IV). One hundred and twenty four men were recorded as having an attack of whooping cough from 1 to 5 years of age. Their mean $F_{E V}$ after adjustment for birth weight was only $0 \cdot 11$ litre lower than that of other men.

Twenty men were recorded as having had measles during infancy, three of whom had also had bronchitis or pneumonia in infancy. In contrast with the findings for whooping cough, the mean $\mathrm{FEV}_{1}$ of these men was 0.17 litre higher than that of all other men, after allowing for birth weight (table IV). The mean volume of the 134 men recorded as having measles between 1 and 5 years was similar to that of all other men.

Mean $\mathrm{FEV}_{1}$ rose progressively by 0.02 litre for each pound increase in weight at 1 year $(0.00$ to 0.03$)$. This trend was greatly weakened after simultaneous adjustment for birth weight whereas the trend in forced expiratory volume with birth weight remained strongly significant. The mean weight at 1 year of the 59 men who had bronchitis or pneumonia during infancy was $0.7 \mathrm{lb}$ less than that of all other men. After allowing for birth weight, the mean reduction of weight at 1 year associated with bronchitis or pneumonia was $0.3 \mathrm{lb}$ $(-0.3$ to $1 \cdot 0)$.

One hundred and twenty seven of the men had never smoked cigarettes, 462 were ex-smokers, and 236 were current smokers. Mean $\mathrm{FEV}_{1}$ fell from 2.69 litres in never smokers to $2 \cdot 52$ litres in ex-smokers and $2 \cdot 29$ litres in current smokers. Table $\mathrm{V}$ shows that this trend occurred at each birth weight. Likewise, the trend of increasing forced expiratory volume with increasing birth weight occurred within each smoking group. Analysis of covariance showed there was no significant 
TABLE $\mathrm{V}-$ Mean forced expiratory volume in one second (litres) adjusted for height and age among men aged 59-70 according to birth weight and smoking habit. Numbers of men in parentheses

\begin{tabular}{|c|c|c|c|c|}
\hline \multirow[b]{2}{*}{$\begin{array}{l}\text { Birth } \\
\text { weight (lb) }\end{array}$} & \multicolumn{3}{|c|}{ Smoking habits } & \multirow[b]{2}{*}{ All } \\
\hline & Never smoker & Ex-smoker & $\begin{array}{l}\text { Current } \\
\text { smoker }\end{array}$ & \\
\hline$\leqslant 5 \cdot 5$ & $2 \cdot 53(4)$ & $2 \cdot 34(16)$ & $2 \cdot 14(13)$ & $2 \cdot 28(33)$ \\
\hline-6.5 & $2 \cdot 48(20)$ & $2 \cdot 46(52)$ & $2 \cdot 29(31)$ & $2.41(103)$ \\
\hline-7.5 & $2.65(37)$ & $2 \cdot 49(154)$ & $2.21(67)$ & $2 \cdot 44(258)$ \\
\hline$-8 \cdot 5$ & $2.77(39)$ & $2.53(134)$ & $2.35(69)$ & $2.52(242)$ \\
\hline$-9 \cdot 5$ & $2.83(19)$ & $2 \cdot 60(75)$ & $2 \cdot 30(38)$ & $2.55(132)$ \\
\hline$>9 \cdot 5$ & $2 \cdot 79(8)$ & $2 \cdot 60(31)$ & $2 \cdot 43(18)$ & $2 \cdot 57(57)$ \\
\hline All & $2 \cdot 69(127)$ & $2 \cdot 52(462)$ & $2 \cdot 29(236)$ & $2 \cdot 48(825)$ \\
\hline
\end{tabular}

difference in the relation of birth weight and $\mathrm{FEV}_{1}$ between the groups. The reductions in $\mathrm{FEV}_{1}$ associated with bronchitis or pneumonia and whooping cough (tables III, IV) were little changed by adjustment for smoking habits.

The social class at birth could be determined in 781 men. Birth weight, infant bronchitis or pneumonia, or whooping cough were not related to social class at birth and neither was adult $\mathrm{FEV}_{1}$. The associations in tables II, III, and IV were found within each social class. $\mathrm{FEV}_{1}$, however, was lower in men with lower current social class. This relation partly depended on the higher prevalence of cigarette smoking in men with lower current social class, though there was a residual relation after allowing for smoking habit.

FVC fell by 0.03 litre for each year of age and rose by 0.04 litre for each centimetre of height. Mean FVC adjusted for age and height showed a weak positive trend with birth weight, which was not significant (table VI). At each birth weight, however, mean FVC was lower in the 59 men recorded as having had bronchitis or pneumonia during infancy. After allowing for the distribution of birth weight the overall mean FVC of the 59 men was $0 \cdot 24$ litre lower (table IV). The mean FVC of the men recorded as having had an attack of bronchitis or pneumonia between 1 and 5 years of age was similar to that of all other men. The mean FVC of the 31 men recorded as having had whooping cough in infancy was 0.31 litre below that of the remaining men (table IV). Recording of measles in infancy or childhood was not associated with differences in FVC (table IV). The mean FVC rose progressively by 0.02 litre for each pound increase in weight at 1 year $(0.00$ to 0.03$)$. The mean FVC fell from

TABLE VI-Mean forced vital capacity (litres) adjusted for height and age among men aged 59-67 according to birth weight and bronchitis or pneumonia in infancy. Numbers of men in parentheses

\begin{tabular}{llll}
\hline \multicolumn{4}{c}{ Bronchitis or pneumonia in infancy } \\
\hline Birth weight $(\mathrm{lb})$ & Absent & Present & All \\
\hline$\leqslant 5.5$ & $2.91(22)$ & $2.88(4)$ & $2.91(26)$ \\
-6.5 & $3.02(70)$ & $2.81(10)$ & $3.00(80)$ \\
-7.5 & $2.94(163)$ & $2.74(25)$ & $2.91(188)$ \\
-8.5 & $3.03(179)$ & $2.76(12)$ & $3.01(191)$ \\
-9.5 & $3.01(103)$ & $2.75(5)$ & $3.00(108)$ \\
$>9.5$ & $3.11(43)$ & $2.57(3)$ & $3.08(46)$ \\
\hline All & $3.00(580)$ & $2.76(59)$ & $2.98^{\star}(639)$ \\
\hline
\end{tabular}

TABLE VII-Odds ratios ( $95 \%$ confidence intervals) of respiratory symptoms in men aged 59-67, according to birth weight and bronchitis or pneumonia in infancy

\begin{tabular}{|c|c|c|c|}
\hline & \multicolumn{3}{|c|}{ Symptom } \\
\hline & Wheezing & $\begin{array}{l}\text { Persistent sputum } \\
\text { production }\end{array}$ & Cough \\
\hline \multicolumn{4}{|c|}{ Birth weight $(\mathrm{lb})$ : } \\
\hline$\leqslant 6.5$ & $1.38(0.88$ to 2.17$)$ & $1.04(0.56$ to 1.92$)$ & $1.04(0.63$ to 1.72$)$ \\
\hline$-8 \cdot 5$ & $1.11(0.73$ to 1.69$)$ & $0.79(0.44$ to 1.43$)$ & $1.04(0.66$ to 1.65$)$ \\
\hline$>8 \cdot 5$ & 1.00 & 1.00 & 1.00 \\
\hline \multicolumn{4}{|c|}{ Bronchitis or pneumonia: } \\
\hline Present & $1.83(1.05$ to 3.20$)$ & $1.73(0.83$ to 3.61$)$ & $1.06(0.54$ to 2.07$)$ \\
\hline Absent & 1.00 & 1.00 & 1.00 \\
\hline
\end{tabular}

$3 \cdot 16$ litres in non-smokers to 2.99 in ex-smokers and 2.84 in current smokers. There was no trend in FVC with social class at birth. It was lower in men with lower current social class. Similarly to $\mathrm{FEV}_{1}$ this relation partly depended on cigarette smoking. The associations with bronchitis or pneumonia and whooping cough were found in each current social class group.

At interview 226 of the men said that they had had wheezing at some time during the past year; 95 brought up sputum first thing on most mornings during three or more months of the year, and 155 usually coughed first thing in the morning. The odds ratio of wheezing was increased in association with lower birth weight and with bronchitis or pneumonia in infancy, though the trend with birth weight was not significant (table VII). Persistent production of sputum was not associated with birth weight but was associated with bronchitis or pneumonia in infancy. Cough was not associated with either birth weight or bronchitis or pneumonia in infancy. None of the three symptoms was associated with whooping cough in infancy.

\section{Discussion}

We examined death rates from chronic obstructive airways disease in a group of 5718 men born in Hertfordshire during 1911-30. We also studied respiratory function in 825 of the men who still live in the county. Their infant weights and childhood illnesses were recorded at the time, and these records allow early growth and illness to be related to death from obstructive airways disease, adult lung function, and respiratory symptoms.

Mean $\mathrm{FEV}_{1}$ fell with decreasing birth weight (table II). This trend was strongly significant and remained so after regression adjustment for current height, age, smoking habit, and social class. The effect of birth weight on $\mathrm{FEV}_{1}$ was independent of the effect of current height, and nearly half as strong. This is remarkable given the imprecise nature of birth weight measurements made over 60 years ago. The association

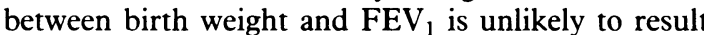
from processes in the selection of our sample as comparisons are made within the sample and the relations are consistent across different levels of social class and smoking habit.

One possible explanation for the association between birth weight and $\mathrm{FEV}_{1}$ is that babies with lower birth weight are more susceptible to lung damage during infancy resulting from adverse influences such as lower respiratory tract infection. However, the trend of falling $F E V_{1}$ with decreasing birth weight was largely independent of the occurrence of lower respiratory tract infection in infancy recorded by health visitors (table III). Furthermore, such adverse influences might be expected to retard infant growth. This is known to occur with lower respiratory tract infection, ${ }^{16}$

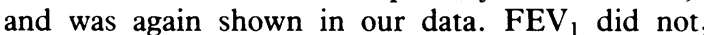
however, fall with decreasing weight at 1 year, independently of birth weight. This suggests that reduced $\mathrm{FEV}_{1}$ is related to lower birth weight independently of an adverse postnatal environment.

We suggest that the association between birth weight and $F E V_{1}$ reflects a direct relation between fetal lung growth and adult lung function. Growth of the airways, "as opposed to growth and expansion of the alveoli, ${ }^{17}$ is largely completed in utero. We conclude that the relation between birth weight and adult FEV may be a consequence of an adverse environment in utero which retards the weight gain of the fetus and irrecoverably constrains the growth of the airways. Such a long term effect of an adverse environment during a critical period of growth is a form of "programming." ${ }^{\prime \prime}$ Experiments in rats have shown that 
malnutrition around the time of birth permanently reduces lung size and DNA content. ${ }^{19}$

We found that men whom health visitors, during periodic visits in infancy, had recorded as having had an attack of bronchitis or pneumonia had a lower mean FEV 1 and FVC (table IV). This observation was independent of birth weight, smoking habit, and social class. Follow up studies of infants with acute lower respiratory tract infection showed that symptoms and abnormal lung function may persis into adolescence. ${ }^{1-3}$ In a national sample of 3261 children born in 1946 and followed up to the age of 36 those whose mothers recalled, at interview two years after the birth, an episode of lower respiratory tract infection had a higher prevalence of winter cough and a lower peak expiratory flow rate. ${ }^{4}$ We found no association between $\mathrm{FEV}_{1}$ and lower respiratory tract infection between the ages of 1 and 5 years. The simplest explanation of these observations is that infection of the lower respiratory tract during a critical period in infancy has persisting deleterious effects.

Several studies have reported that whooping cough is not followed by persisting symptoms or abnormalities of lung function during childhood or early adult life. ${ }^{2021}$ In one study, however, persisting effects were found in those infected during infancy. ${ }^{22}$ We found that men recorded as having whooping cough in infancy had a lower mean $\mathrm{FEV}_{1}$ (table III) and FVC (table IV) independently of a history of bronchitis or pneumonia and independently of birth weight, smoking habit, and social class. The occurrence of whooping cough from 1 to 5 years was associated with smaller reductions in $\mathrm{FEV}_{1}$ and $\mathrm{FVC}$ (table IV).

Measles infection was not related to a reduction in either $\mathrm{FEV}_{1}$ or FVC (table IV). This is surprising as measles was a common antecedent of bronchitis and pneumonia 70 years ago. ${ }^{23}$ Furthermore, the geographical distribution of infant deaths from measles in England and Wales 70 years ago was similar to the present distribution of deaths from obstructive lung disease. ${ }^{5}$ Given the difficulty of diagnosing measles during infancy, some infants with little or no rash may have been recorded as having bronchitis or pneumonia. Alternatively, measles tends to affect infants at an older age than does whooping cough, and the lungs may therefore be infected at a time when they are growing less rapidly.

Measurements taken with a turbine pocket spirometer are as repeatable as those taken with a Vitalograph, although the values given are slightly lower..$^{2425}$ Previous studies with turbine pocket spirometers (as opposed to pneumotachograph microspirometers) did not show any significant downward drift in readings with time. We found no drift in recordings of $\mathrm{FEV}_{1}$, although a small downward drift occurred in recordings of FVC during the study. In our study FVC was not related to birth weight but was reduced in men who had a lower respiratory tract infection in infancy (table IV), in those with lower weight at 1 year, and in those who smoked. These relations were unaltered by adjustment for the drift in readings of FVC with regression. Notwithstanding the difficulties in measuring, an interpretation of these findings is that the components of lung behaviour which determine FVC, as opposed to $\mathrm{FEV}_{1}$, are programmed in infancy rather than intrauterine life. This interpretation is supported by a study of 250 children aged 7 years whose FVC was not related to birth weight but whose $\mathrm{FEV}_{1}$ was. ${ }^{10}$

In keeping with the results for forced expiratory volume, men who were of lower birth weight or had had bronchitis or pneumonia in infancy were more likely to report wheezing (table VII). Persistent sputum production, however, was not associated with lower birth weight but with bronchitis or pneumonia in infancy. This is consistent with the hypothesis that chronic airflow obstruction, indicated by a reduced $\mathrm{FEV}_{1}$ and wheezing, and mucus hypersecretion, indicated by sputum production, are different diseases that often coexist. ${ }^{13} \mathrm{~A}$ follow up study of men whose lung function and respiratory symptoms had been assessed in adult life showed that the risk of death from chronic obstructive airways disease was strongly correlated with the initial $\mathrm{FEV}_{1}$. Symptoms of mucus hypersecretion were, however, a poor predictor of death from chronic obstructive airways disease. ${ }^{1+}$

Death rates from chronic obstructive airways disease but not from another disease related to smoking, lung cancer, fell with increasing birth weight and weight at 1 year (table I). This is consistent with the strong relation between birth weight and forced expiratory volume and the relation between infant bronchitis or pneumonia and lower weight at 1 year. There were, however, only 55 deaths. Continued follow up and extension of the study to the entire county will bring greater statistical power.

One interpretation of our findings could be that the association of lower birth weight and infant respiratory infection with adult lung function merely reflects maternal smoking. The men in our sample, however, were born at a time when maternal smoking was uncommon. Although paternal smoking was common at the time, much disagreement still surrounds the issue of whether paternal smoking is associated with low birth weight, ${ }^{2627}$ and the magnitude of the effect, if any, is likely to be small. Earlier this century mothers' physique, nutrition, and health were the major determinants of fetal growth, and infant respiratory infection was linked with poor housing, large families, and overcrowding. ${ }^{5}$ Prevention of chronic obstructive airways disease may partly depend on promotion of fetal and infant lung growth and reduction in the incidence of lower respiratory tract infection in infancy.

We thank the men in Hertfordshire who gave us their time; Hertfordshire County Archives, who preserved the records; the staff of NHSCR Southport and Hertfordshire Family Health Services Authority who traced the men; and Dr I Clarke, district community physician, who helped with the survey. The fieldwork was organised by A Lee and carried out by $\mathbf{P}$ Harwood, S Haynes, P Howell, R Rosenthal, and S Wolfe. The study was assisted by grants from the Dunhill Medical Trust and the Wessex Medical School Trust. SOS has a Wellcome Trust fellowship.

1 Pullan CR, Hey EN. Wheezing, asthma, and pulmonary dysfunction 10 years after infection with respiratery syncytial virus in infancy. BMF 1982:284: after inf

2 Kattan M, Keens TG, Lapierre J-G, Levison H, Bryan C, Reilly BJ Pulmonary function abnormalities in symptom-free children after bronchiolitis. Pediatrics 1977;59:683-8.

3 Mok JYQ, Simpson H. Outcome for acute bronchitis, bronchiolitis and pneumonia in infancy. Arch Dis Child 1984;59:306-9.

4 Britten N, Davies JMC, Colley JRT. Early respiratory experience and subsequent cough and peak expiratory flow rate in 36 year old men and women. BMJ 1987;294:1317-20.

5 Barker DJP, Osmond C. Childhood respiratory infection and adult chronic bronchitis in England and Wales. BMf 1986;293:1271-5.

6 Reid DD. The beginnings of bronchitis. Proc $R$ Soc Med 1969;62:311-6.

7 Osmond C, Slattery JM, Barker DJP. Mortality by place of birth. HMSO London, 1990. (Series DS, No 9.)

8 Reid DD, Fletcher CM. International studies in chronic respiratory disease. Br Med Bull 1971;27:59-64. 9 McCall MG, Acheson ED. Respiratory disease in infancy. F Chronic Dis

10 Chan KN, Noble-Jamieson CM, Elliman A, Bryan EM, Silverman M. Lung function in children of low birth weight. Arch Dis Child 1989;64:1284-93.

11 Bucher U, Reid L. Development of the intrasegmental bronchial tree: the pattern of branching and development of cartilage at various stages of intra-
a pattern of branching and developmento
uterine life. Thorax 1961;16:207-18.

12 Medical Research Council. Questionnaire on respiratory symptoms. London: MRC, 1986.

13 Fletcher $C M$, Peto R. The natural history of chronic airflow obstruction. $B M \gamma$ 1977;i: 1645-8.

14 Peto R, Speizer FE, Cochrane AL, Moore F, Fletcher CM, Tinker CM, et al. The relevance in adults of air-flow obstruction, but not of mucus hypersecretion, to mortality from chronic lung disease. Am Rev Respir Dis 1983;128:491-500

15 Breslow NE, Day NE. Statistical methods in cancer research. Vol 1. The analysis of case control studies. Lyons: International Agency for Research on Cancer, 1980.

16 Rowland MGM, Rowland SGJG, Cole TJ. Impact of infection on the growth of 
children from 0 to 2 years in an urban west African community. Am $7 \mathrm{Clin}$ Nutr 1988:47:134-8

Thorthat human lung growth. Thorax 1982;37:564-71.

18 Bock GR, Marsh J, eds. The childhood environment and adult disease. Chichester: Wiley, 1991. (Ciba Foundation Symposium No 156.

19 Winick $M$, Noble A. Cellular response in rats during malnutrition at various ages. F Nutrition 1966;89:300-6.

Johnston IDA, Lambert HP, Anderson HR, Patel S. Respiratory morbidity and lung function after whooping cough. Lancet 1983;ii:1104-8.

21 Britten N, Wadsworth J. Long term respiratory sequelae of whooping cough in nationally representative sample. $B M 7$ 1986;292:441-4.

22 Swansea Research Unit of the Royal College of General Practitioners. Respiratory sequelae of whooping cough. BMF 1985;290:1937-40.
23 Halliday JL. An inquiry into the relationship between housing conditions and the incidence and fatality of measles. London: Medical Research Council, 1928. MRC Specia Report Series No 120 .

24 Gunawardena KA, Houston K, Smith AP. Evaluation of the turbine pocket spirometer. Thorax 1987;42:689-93.

25 Hosie HE, Nimmo WS. Measurement of $\mathrm{FEV}_{1}$ and FVC. Comparison of pocket spirometer with the Vitalograph. Anaesthesia 1988;43:233-8.

26 Chen Y, Pederson LL, Lefcoe NM. Passive smoking and low birth weight Lancet 1989;ii:54-5.

27 Davis DL. Paternal smoking and fetal health. Lancet 1991;337:123.

(Accepted 4 fuly 1991)
Aker University Hospital, 0514 Oslo 5, Norway

Helge Kapelrud, MD, senior registrar

Hans-Jacob Bangstad, MD, senior registrar

Knut Dahl-Jørgensen, MD, consultant

Kristian F Hanssen, MD, consultant

Institute of Medica Genetics, University of Oslo, Box 1036 Blindern, 0315 Oslo 3, Norway

Kåre Berg, $\mathrm{MD}$, professor

Correspondence to: $\mathrm{Dr} \mathrm{H}$ Kapelrud, Department of Medicine, Hamar Sjukehus, 2300 Hamar, Norway.

BMF 1991;303:675-8

\title{
Serum $L p(a)$ lipoprotein concentrations in insulin dependent diabetic patients with microalbuminuria.
}

\author{
Helge Kapelrud, Hans-Jacob Bangstad, Knut Dahl-Jørgensen, Kåre Berg, Kristian F Hanssen
}

Abstract

Objective-To compare the serum concentrations of lipoproteins and apolipoproteins in insulin dependent diabetic patients with and without microalbuminuria.

Design-Cross sectional study.

Setting-Paediatric and medical outpatient clinic at a university hospital.

Patients - 76 insulin dependent diabetic patients: 41 with microalbuminuria (20 males, 21 females) and 35 controls without microalbuminuria (18 males, 17 females). The two groups were similar with respect to age, duration of disease, and haemoglobin $A_{1 c}$ concentrations before the study.

Main outcome measures-Serum concentrations of $L p(a)$ lipoprotein, total cholesterol, high density lipoprotein cholesterol, very low density lipoprotein cholesterol, low density lipoprotein cholesterol, triglycerides, and apolipoproteins A-I, A-II, and B.

Results-Median serum $L p(a)$ lipoprotein concentration was $10.0 \mathrm{mg} / 100 \mathrm{ml}$ in the microalbuminuric group and $4.9 \mathrm{mg} / 100 \mathrm{ml}$ in the control group $(p=0.007) .17(41 \%)$ of the microalbuminuric patients and five $(14 \%)$ of the control patients had $\mathbf{L}$ (a) lipoprotein values above the upper quartile of a normal population. Median serum triglycerides concentrations in the microalbuminuric and control groups were $1.15 \mathrm{mmol} / \mathrm{l}$ and $0.88 \mathrm{mmol} / \mathrm{l}$ respectively $(\mathbf{p}=\mathbf{0} \cdot 03)$. Median very low density lipoprotein cholesterol concentration was $0.52 \mathrm{mmol} / \mathrm{l}$ in the microalbuminuric group and $0.40 \mathrm{mmol} / 1$ in the control group $(p=0.03)$. No significant differences in serum concentrations of total cholesterol, high density lipoprotein cholesterol, low density lipoprotein cholesterol, or apolipoproteins A-I, A-II, and $B$ were found between the groups.

Conclusions-Serum concentrations of $L p(a)$ lipoprotein are twice as high in insulin dependent diabetic patients with microalbuminuria as in those without microalbuminuria. Increased concentrations of $L p(a)$ lipoprotein might partly explain the increased morbidity and mortality from cardiovascular disease observed among patients with diabetic nephropathy.

\section{Introduction}

Mortality is 40 times higher in insulin dependent diabetic patients with nephropathy than in those without this complication. ${ }^{1}$ Much of the excess mortality is caused by cardiovascular disease. ${ }^{2}$ Forty per cent of diabetic patients develop coronary heart disease within six years after manifesting nephropathy. ${ }^{3}$ Such patients have increased blood pressure, atherogenic lipid and lipoprotein patterns, and changes in the balance between coagulation and fibrinolysis in favour of coagulation, ${ }^{+6}$ but these cardiovascular risk factors cannot explain the substantial increase in mortality. Patients with incipient nephropathy (persistent microalbuminuria) may have the same cardiovascular risk factors, but to a lesser extent. ${ }^{48}$ Diabetic patients with incipient nephropathy are at risk of developing proteinuria within 10 years. ${ }^{9} 10$

$\mathrm{Lp}$ (a) lipoprotein contains less lipid and more protein than low density lipoprotein, although both contain apolipoprotein B. Lp(a) lipoprotein has a unique long, highly glycated polypeptide chain ( $\mathrm{Lp}(\mathrm{a})$ apolipoprotein) which carries the $L p(a)$ antigens. The gene for $\mathrm{Lp}(\mathrm{a})$ apolipoprotein has been cloned and extensive homology with plasminogen has been found."

The concentration of $\mathrm{Lp}(\mathrm{a})$ lipoprotein in serum is determined genetically. ${ }^{12-16}$ Since the first report in $1974,{ }^{17}$ several investigators have confirmed that a high $\mathrm{Lp}$ (a) lipoprotein concentration is an independent risk factor for cardiovascular disease. ${ }^{16-20} \mathrm{Lp}(\mathrm{a})$ lipoprotein has been detected in atherosclerotic lesions in amounts reportedly reflecting the serum concentration, ${ }^{21}$ suggesting that it may be atherogenic. Because of the homology with plasminogen it has been hypothesised that the $\operatorname{Lp}(\mathrm{a})$ lipoprotein may provide a link between atherogenesis and thrombus formation..$^{22}$

As diabetic nephropathy is linked with atherosclerotic disease and as the diabetic patients with microalbuminuria are those who develop nephropathy, we investigated whether insulin dependent diabetic patients with microalbuminuria have an increased plasma concentration of $L p(a)$ lipoprotein compared with diabetic controls without microalbuminuria.

\section{Patients and methods}

We recruited 41 patients, 20 males and 21 females with insulin dependent diabetes mellitus and microalbuminuria from our hospital's outpatient clinic on the basis of hospital records of microalbuminuria. All patients had had onset of diabetes before the age of 30 . We defined microalbuminuria as albumin excretion $\geqslant 15 \mu \mathrm{g} / \mathrm{min}$ and $\leqslant 200 \mu \mathrm{g} / \mathrm{min}$ in at least two consecutive or two of three timed overnight urine samples. The urine samples did not show leucocyturia when tested by dipsticks. None of the patients had a history of non-diabetic renal disease, and none had ketoacidosis at the time of sampling.

The patients with microalbuminuria were compared with 35 insulin dependent diabetic patients without microalbuminuria. The sex ratio, age, duration of diabetes, and concentrations of haemoglobin $A_{l c}$ (means of three values) were similar in both groups. Haemoglobin $A_{1 c}$ concentrations were measured over 12 to 15 months, starting from 12 to 28 months and 